\title{
Contraception usage among young adult men in a developing country
}

This article was published in the following Dove Press journal:

Open Access Journal of Contraception

23 July 2010

Number of times this article has been viewed

\section{Paul A Bourne' Christopher AD Charles ${ }^{2,3}$ \\ 'Department of Community Health and Psychiatry, Faculty of Medical Sciences, University of the West Indies, Mona, Kingston, Jamaica; ${ }^{2}$ King Graduate School, Monroe College, Bronx, New York, NY, USA; ${ }^{3}$ Center for Victim Support, Harlem Hospital Center, New York, NY, USA}

Background: Jamaica is a Third World country with an increasing population and public resource constraints to address development imperatives, one of which is reproductive health. Aims: This study examines the method of contraception used by men in Jamaica and the factors that influence their choice of contraceptives.

Materials and methods: The investigation was carried out with a stratified random sample of 2,437 men drawn from the National Family Planning Board dataset of men aged 15-24 The measures included variables such as age, crowding, area of residence, church attendance, method of contraception used, being in a relationship, the number of partners, having a pregnant woman partner, and being sexually active among other variables.

Results: The majority of the men had engaged in sexual intercourse in the last 30 days. Frequent church attendance increased sexual abstinence. The majority of the men who mostly got their contraceptives from the pharmacy mostly used a condom. Lesser used methods were the pill and the rhythm method, among others. The method of contraception used was significantly determined by having had sexual intercourse in the last 30 days with a nonsteady partner $(\mathrm{OR}=2.00$, 95\% CI: 1.40-2.86), sharing sanitary facilities with a nonhousehold member ( $\mathrm{OR}=0.62,95 \%$ CI: $0.42-0.94)$ and having a pregnant partner (OR $=0.08,95 \% \mathrm{CI}: 0.04-0.16)$.

Conclusion: A national reproductive health policy is needed that takes into account the type of contraceptives used, the institutional sources of information, the sources of contraceptives, the risk of sexually transmitted infections, and the three explanatory factors for the methods of contraception used.

Keywords: young men, reproductive health, contraception, sexual relations, developing nation

\section{Introduction}

The purpose of this article is to understand the use of contraceptive methods by males aged 15-24 years in Jamaica. Jamaica is a Third World country with an ever-increasing population, and public resource constraints to address development imperatives, one of which is reproductive health. There is a dearth of published research on the reproductive health of Jamaican males, so this article is a modest effort to address the issue. Among some low-income men, family planning is viewed as fathering the number of children a man can provide for. Although most of the men had poor and misconceived knowledge, they were nonetheless aware of the traditional and modern methods of birth control. The men believed that the use of these modern methods discouraged family planning and led to side effects. The family planning methods were not used because children are considered a source of wealth. ${ }^{1}$
Correspondence: Paul A Bourne Department of Community Health and Psychiatry, UWI, Mona, Jamaica Tel +18764576990

Email paulbournel@yahoo.com
Open Access Journal of Contraception 2010:1 51-59

(C) 2010 Bourne and Charles, publisher and licensee Dove Medical Press Ltd.This is an Open Access

Dovepress

11491 
One study showed that the use of contraceptives by wives was a function of the encouragement their husbands received from social networks, which triggers communication between the partners about reproductive health. ${ }^{2}$ Whenever partners engage in mutual decision-making about the use of contraceptives and sexual activities, men are construed as the initiators of sexual intercourse, and women are more likely to suggest that they use a condom. ${ }^{3}$ However, religious influence can be disruptive in mutual decision-making about reproductive health. One study found that $63 \%$ of men did not use condoms for religious reasons, and did not want their women to use contraceptives. ${ }^{4}$ Similarly, masculine identity influences reproductive health decision-making in intimate partner relationships. Some men keep the decision about the use of contraceptives under their control when they are negotiating their masculine identity during sexual intercourse. ${ }^{5}$

College men who had sexual intercourse in the last 30 days for the first time were younger than a similar cohort of college women. More often than not these men had their first encounter with someone to whom they were not emotionally attached. Some $60 \%$ of the men did not use a method of contraception, or the method they used was unreliable. The most frequent reason reported by the men for not using a contraceptive was that the encounter was unplanned. The nonuse of contraceptives was also influenced by the men's inaccessibility to sources of contraceptives and their lack of knowledge. Some $21.9 \%$ of the men said they did not use a contraceptive because it was inconvenient. ${ }^{6}$ Despite the availability of the pill, the rate of unwanted pregnancies among adolescents has grown significantly. Therefore, increasing men's involvement in contraception can make a difference to the trend of unwanted pregnancies. ${ }^{?}$

Men's involvement is indeed relevant, because among mature men, perceived behavioral control and belief about condom use are important in reproductive health. An online survey of men's attitudes and beliefs towards male hormonal contraceptives (MHC) suggests that, in general, perceived behavioral control was the most significant predictor of their intention to try MHC. The men's belief about condom use was the most significant predictor of the use of MHC along with condoms. Some $56 \%$ of the men stated that MHC would reduce their use of condoms. ${ }^{8}$ Targeting men when they are watching sports is of critical importance. Reproductive health information disseminated during football games, and the presentation of other sport-related images, are particularly useful in reaching men about the long-term use of modern contraceptives. ${ }^{9}$
The purpose of this article is to understand the reproductive health of males aged 15-24 years in Jamaica. Reproductive health is an issue of critical importance in this developing country because it affects development targets in general and the health system in particular, through population growth. Below is the method of data collection used in the study.

\section{Methods}

Sample

This descriptive cross-sectional study used a secondary dataset from the National Family Planning Board (NFPB). There are two sets of inclusion criteria, which are males and ages. The eligibility criterion for age was 15-24 years at last birthday. Since 1997, the NFPB has been collecting information on men (aged 15-24 years) and women (aged 15-49 years) in Jamaica regarding contraception usage and/or reproductive health. In 2002, the Reproductive Health Survey (RHS) collected data on Jamaican men aged 15-24 years and women aged 15-49 years. The current study, using 2,437 men, extracted the sample of men (aged 15-24 years). The inclusion and/or exclusion criterion was young males (aged 15-24 years).

Stratified random sampling was used to design the sampling frame from which the sample was drawn. Using the 2001 Census sector (or sampling frame), a three-stage sampling design was used. Stage 1 was the use of a selection frame of 659 enumeration areas (or enumeration districts [EDs]). This was calculated based on probability proportion to size. Jamaica is classified into four health regions. Region 1 is composed of Kingston, St. Andrew, St. Thomas, and St. Catherine; Region 2 comprises Portland, St. Mary, and St. Ann; Region 3 is made up of Trelawny, St. James, Hanover, and Westmoreland, with Region 4 being St. Elizabeth, Manchester, and Clarendon. The 2001 Census showed that Region 1 comprised 46.5\% of Jamaica compared with Region 2 at 14.1\%, Region 3 at $17.6 \%$, and Region 4 at $21.8 \% .^{10}$

In stage 2 the households were clustered into primary sampling units (PSUs), and each PSU constituted an ED, which in turn was comprised of 80 households. The previous sampling frame was in need of updating, and so this was performed between January and May 2002. On completion of the exercise, the total number of households visited was 15,950 of which $17.5 \%$ of the inhabitants dwelled in urban areas, $27.7 \%$ resided in semi-urban zones and $54.8 \%$ lived in rural areas. Almost $18 \%$ of the households had eligible men (aged 15-24 years old, $n=2,795$ men). Sixteen percent 
of the eligible men resided in urban areas, $27.7 \%$ lived in semi-urban areas, and 56.4\% dwelled in rural areas. The new sampling frame formed the basis upon which the sampling size was computed for the interviewers to use. The sample represents a response rate of $87.2 \%: 88.3 \%$ of eligible urban men, $88.0 \%$ of semi-urban, and $86.7 \%$ of eligible rural respondents.

Stage 3 was the final selection of one eligible male from each sampled household, and this was done by the interviewer on visiting the household.

The Statistical Institute of Jamaica (STATIN) provided the interviewers and supervisors, who were trained by McFarlane Consultancy, to carry out the survey. The instrument administered was a 35-page questionnaire. The data collection began on Saturday, October 26, 2002 and was completed on May 9, 2003. Prior to the date of the final data collection, pretesting of the instrument was conducted between March 16 and 20,2002. A total of 175 instruments were pretested, of which $40.6 \%$ were given to eligible men. Modifications were made to the pretested instrument (questionnaire), after which the final exercise was carried out. The data was weighted in order to represent the population of men aged 15-24 years in the nation.

\section{Statistical methods}

We used the Statistical Packages for the Social Sciences (SPSS) for Windows (Version 16.0; SPSS Inc., Chicago, IL, USA). Frequencies and means were computed on the sociodemographic characteristics. We also performed $\chi^{2}$ tests and F-tests to evaluate associations and differences among mean scores. Stepwise multiple logistic regressions were used to analyze factors that explain the current usage of a contraceptive method. Odds ratios were determined from the use of a binary logistic regression model. Where collinearity existed $(r>0.7)$, variables were entered independently into the model to determine those that should be retained during the final construction of the model. ${ }^{11}$ To derive accurate tests of statistical significance, we used SUDDAN statistical software (Research Triangle Institute, Research Triangle Park, NC, USA), and this was adjusted for the survey's complex sampling design. A $P$-value $<0.05$ (two-tailed) was used to determine statistical significance.

\section{Measure}

Crowding was the total number of persons who dwell in a room (excluding kitchen, bathroom and verandah). Age was measured using "What is your age at last birthday? (in years)". Contraceptive method was any device or approach that is used to prevent pregnancy. These methods include tubal ligation, vasectomy, implant (norplant), injection, emergency contraceptive protection, pill, condom, foaming tablets, creams, jellies, diaphragm, abstinence, withdrawal, the rhythm method, calendar, or Billings. The dependent variable for this study was a contraceptive method which was coded as a binary variable from those who indicated yes to any of the aforementioned methods of contraception. Nonsteady sexual partner denotes casual sexual relations with someone with whom the individual is not having a common-law sexual relationship, visiting relationship or to whom the individual is legally married. Education is taken from the question "How many years did you attend school?" This is coded as primary or below ( $0-9$ years), secondary (10-12 years), and tertiary (13+ years). Age at first sexual intercourse is measured from "At what age did you have your first intercourse?" Contraceptive method comes from the question "Are you and your partner currently using a method of contraception ...", and if the answer is yes "Which method of contraceptive do you use?". Shared sanitary facility is measured from the question "What type of toilet facilities (or bathroom) does this household have?" and "Are these facilities shared with another household?". The options are shared, not shared or not stated. This was coded as 1 $=$ shared and $0=$ otherwise. Number of sexual partners is taken from the question "How many 'baby mothers' (including wives) have you had?". Religiosity was evaluated from the question "With what frequency do you attend religious services?". The options range from at least once per week to only on special occasions (such as weddings, funerals, christenings, et cetera). Currently having sex denotes have had sexual intercourse in the last 30 days. This is measured using the question "Have you had sexual intercourse in the last 30 days?". Marital status is measured from the following questions: “Are you legally married now?”, “Are you living with a common-law partner now; that is, are you living as man and wife with a partner to whom you are not legally married?", "Do you have a visiting partner, that is, a more or less steady partner with whom you have sexual relations?", and "Are you currently single?".

\section{Model}

Using logistic regression, this study seeks to examine factors associated with the methods of contraception used among men in Jamaica. Different social factors influence men's choices, and their decision to use a method of contraception, and this study used Grossman's model, which established a connection between the use of econometric analysis and the 
use of health demand. Grossman's model has been modified and used by many scholars to examine health, health outcome, and other health-related issues.

The current research will use the theoretical framework of Grossman's econometric analysis to examine factors that are associated with the method of contraception usage among men ages 15-24 years in Jamaica. The variables used in this econometric model are based on the literature as well as the dataset. We will test the hypothesis that the method of contraception usage among men aged 15-24 years is determined by particular sociodemographic variables.

Based on the literature, the following variables were examined using logistic regression: Dependent - method of conceptive used. Independent - age of respondents; educational level; employment status of young adult man; social class of young adult man; area of residence; someone currently pregnant for respondent; forced to have sex (young adult); shared sanitary convenience with nonhousehold members; age of first sexual relations; currently had sexual intercourse in the last 30 days; number of sexual partners; religiosity; currently in a sexual union; hearing family planning message; crowding in household; age at which began using contraceptive method; involvement in family planning program; marital status and having had sexual intercourse in the last 30 days with a nonsteady partner.

\section{Results}

Table 1 presents information on the sociodemographic characteristics of the sample. Almost 59\% of the sample had their first sexual encounter between 15 and 19 years, and $41 \%$ between ages 20 and 24 years.

When respondents were asked "Which is your preferred source of information about family life or sex education topics?", marginally more indicated teacher $(25.4 \%)$ than parent/guardian $(22.5 \%)$, peers/friends $(20.6 \%)$, sibling $(13.5 \%)$, telephone counselor $(13.5 \%)$ and lastly by radio $(1.2 \%)$. None of the respondents indicated television, audiovisual materials and printed materials.

When the respondents were asked "What is the method of contraception that was used by themselves or their partners that last time they had sexual relations?", $60.5 \%$ indicated a male condom, 3.4\% said the pill, $0.1 \%$ claimed the emergency contraceptive protection, $1.0 \%$ stated the rhythm or calendar method, and $32.9 \%$ did not respond to the question. Sixty-three percent of the sample indicated that they have had sex with a nonsteady partner. Of those who have had sex with a nonsteady partner, $72.4 \%$ indicated that they have always used a condom, 22.7\% said
Table I Demographic characteristic of sample, $n=2,437$

\begin{tabular}{|c|c|}
\hline Characteristic & $\%$ \\
\hline \multicolumn{2}{|l|}{ Educational level } \\
\hline Junior high or below & 9.3 \\
\hline Secondary & 42.9 \\
\hline Tertiary & 47.8 \\
\hline \multicolumn{2}{|l|}{ Marital status } \\
\hline Legally married & 3.9 \\
\hline Common-law & 40.3 \\
\hline Visiting & 17.1 \\
\hline Not currently in union & 38.7 \\
\hline \multicolumn{2}{|l|}{ Had sex in the past } \\
\hline Yes & 81.3 \\
\hline No & 18.7 \\
\hline \multicolumn{2}{|c|}{ Currently had sexual intercourse in the last } \\
\hline \multicolumn{2}{|l|}{ four weeks (in the last 30 days) } \\
\hline Yes & 53.2 \\
\hline No & 46.8 \\
\hline \multicolumn{2}{|c|}{ Currently using a method of contraception } \\
\hline Yes & 82.7 \\
\hline No & 17.3 \\
\hline \multicolumn{2}{|l|}{ Employment status } \\
\hline Employed & 34.1 \\
\hline Unemployed & 65.9 \\
\hline \multicolumn{2}{|l|}{ Area of residence } \\
\hline Urban & 16.2 \\
\hline Semi-urban & 27.9 \\
\hline Rural & 55.9 \\
\hline \multicolumn{2}{|c|}{ Shared facilities (sanitary convenience or water) } \\
\hline Shared & 13.8 \\
\hline Not shared & 84.8 \\
\hline Not stated & 1.4 \\
\hline \multicolumn{2}{|l|}{ Someone currently pregnant for you } \\
\hline Yes & 2.1 \\
\hline No & 97.9 \\
\hline \multicolumn{2}{|l|}{ Frequency of condom usage } \\
\hline Always & 23.9 \\
\hline Most times & 28.1 \\
\hline Sometimes & 9.7 \\
\hline Never & 2.1 \\
\hline Have no steady partner & 11.6 \\
\hline Refused to answer & 24.6 \\
\hline \multirow[t]{2}{*}{ Age mean (SD) } & 19.0 years \\
\hline & ( 2.8 years) \\
\hline \multirow[t]{2}{*}{ Age of first sexual relations mean (SD) } & 14.9 years \\
\hline & (3.I years) \\
\hline
\end{tabular}

they used a condom most of the time, $1.7 \%$ said they have never used a condom, and 3.2\% claimed that they seldom used a condom.

A significant statistical association existed between frequent church attendance and area of residence $\left(\chi^{2}=45.9\right.$, $P$-value $<0.0001)$. Almost $25 \%$ of urban respondents attended church at least once a week, compared with $23 \%$ of those who dwelled in semi-urban zones and 21\% in rural areas.

Figures 1 and 2 present information on contraceptive methods, having had sex in the last 30 days, and having never 


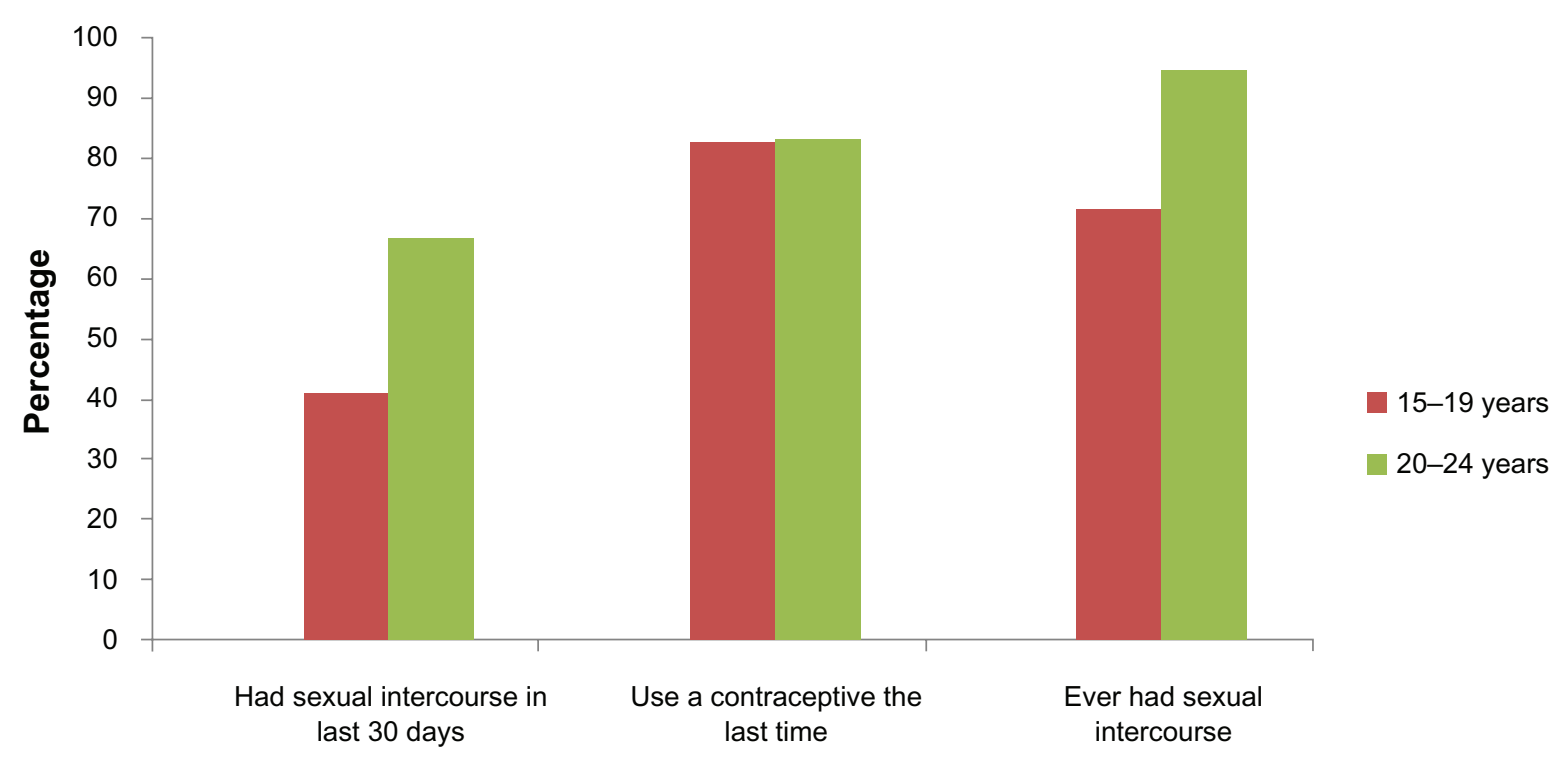

Figure I Attitude and practices on reproductive health issues by age group.

had sexual intercourse, by age group of respondents. Figure 3 shows information on the method of contraception used by respondent or respondent's partner by age group.

Table 2 provides information on source of family life or sex education by age group of respondents.

Using logistic regression analyses, three variables emerged as statistically significant determinants of the current contraceptive methods of the participants (Table 3).

\section{Discussion}

This study examined the method of contraception used by Jamaican males and the factors that influenced their decisions.
The overwhelming majority of men (81\%) have had sex, but only $53 \%$ had sexual intercourse in the last 30 days. However, only $24 \%$ among the currently sexually active males always used a condom. The most prevalent method of contraception used by the men is condoms (60.5\%) with pills, emergency contraceptives, and the rhythm method accounting for $4.5 \%$ of the other methods, based on the descending order of use. A large proportion of the men (63\%) had sex with a nonsteady partner, with $72.4 \%$ of this group declaring that they always used a condom. This finding means that just under $30 \%$ of the men who were sleeping with multiple partners did not always use a condom, which increased their risk of sexually transmitted infections (STIs). Hence when studies reveal the

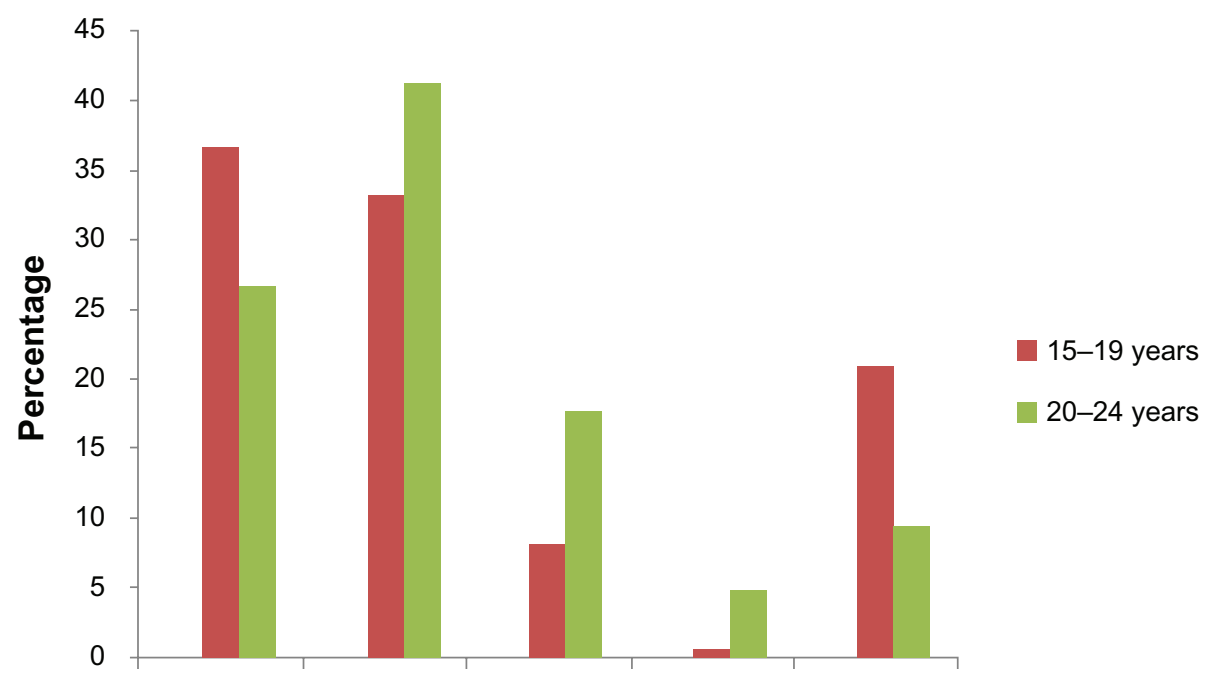

Figure 2 Frequency of condom usage by age group. 


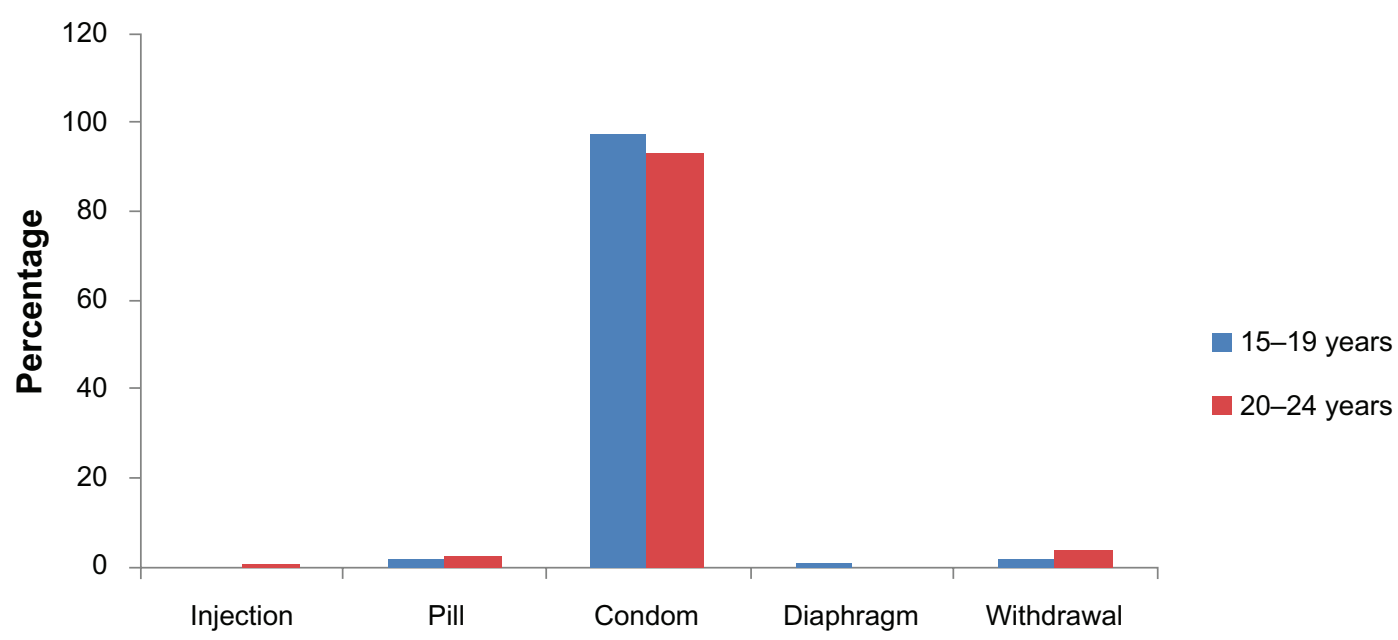

Figure 3 Method of contraception used by respondent or respondent's partner by age group.

method of contraception usage among people of a particular gender, socioeconomic status, or other demographic characteristics ${ }^{12-14}$ without providing information on the frequency of the usage of the contraceptive method, it does not give a true picture of their reproductive practices. The current study found that $83 \%$ of young males were currently using a contraceptive method, but that only $24 \%$ always used a condom and $28 \%$ remarked most times, which means that the prevalence of $83 \%$ contraceptive usage would be excellent, and speaks volumes about the seemingly healthy lifestyle practices of young males. However, this becomes farther from the truth when the data are examined using frequency of contraceptive method usage. This research, therefore, provides a better understanding of young men's reproductive attitudes, and their involvement in risky sexual practices, and not merely the usage prevalence of a male method of contraception. The findings which emerged from this study also support other studies that have examined men's health and men's reproductive attitudes and practices. ${ }^{15-17}$

Despite their awareness of the probability of contracting HIV or AIDS owing to unsafe sexual practices, there are still many men who do not frequently use a condom. It may appear difficult to understand that there is not an increase in frequent condom usage or condom usage among men in different geopolitical regions, as is the case in this study, ${ }^{18-22}$ but a part of this is embedded in the culture which ties masculinity to fertility. A Caribbean anthropologist, in a Caribbean research, found that young males are socialized to be strong, eschew weakness, have many women and children as well as avoid health care utilization, because this is interpreted as weakness. ${ }^{23}$ Embedded in Chevannes' findings ${ }^{23}$ is a sociological explanation as to why young Caribbean males would be reluctant to frequently use a condom. Maleness or manhood, according to Chevannes ${ }^{23}$ means taking risks. Sexual risk-taking is among many risks that men take, and so reluctance towards condom usage is one more risk that young males would be more likely to take, in comparison to older men who have material resources, family and have had many of the experiences that young males are involved in.

Some $53 \%$ of the men indicated that they did not use a method of contraception when they had sexual intercourse for the first time. The majority of these men (54.8\%) had their first sexual intercourse with a woman to whom they were not emotionally attached in a relationship. These findings corroborate those of the study done by Needle,${ }^{6}$ that the majority of men in college who had their first sexual intercourse did so without a contraceptive and with a woman to whom they were not emotionally attached. There are other similarities between the findings of the study done by Needle and the findings of the current study. The first sexual intercourse was unplanned for $38 \%$ of the men in the current study, $16 \%$ did not have access to a contraceptive at the time of their first sexual intercourse, and 30\% displayed a lack of knowledge about methods of contraception. Despite these findings, the majority of the men (60.8\%) used a condom in their last sexual intercourse to prevent pregnancy and STIs. However, the foregoing finding means that $15 \%$ of the men who recently had sex and used a condom used it only for preventing STIs or pregnancy, because $25 \%$ of the men stated that they did not know why they used a condom. It is possible that their female partner asked these men to use a condom. Nevertheless, these men need to be educated to understand that the use of condoms prevents not only pregnancy but also STIs. This education is of the utmost importance, given the negative 
Table 2 How helpful have you found the following sources? Listed by age group, $\mathrm{n}=2,437$

\begin{tabular}{|c|c|c|c|}
\hline \multirow[t]{3}{*}{ Characteristic } & \multicolumn{2}{|l|}{ Age group } & \multirow[t]{3}{*}{$P$-value } \\
\hline & $15-19$ yrs. & $20-24$ yrs. & \\
\hline & $\%$ & $\%$ & \\
\hline \multicolumn{4}{|l|}{ Helpful of sources } \\
\hline Parents/guardians & & & $\chi^{2}=9.772, P=0.021$ \\
\hline Very helpful & 56.6 & 50.8 & \\
\hline Somewhat helpful & 21.7 & 22.9 & \\
\hline Not helpful & 12 & 15.3 & \\
\hline Not a source & 9.7 & 11 & \\
\hline Sibling & & & $\chi^{2}=0.733, P=0.866$ \\
\hline Very helpful & 23 & 23.1 & \\
\hline Somewhat helpful & 22.3 & 23.7 & \\
\hline Not helpful & 21.5 & 21.3 & \\
\hline Not a source & 33.2 & 32 & \\
\hline Telephone counselor & & & $\chi^{2}=4.008, P=0.26 \mathrm{I}$ \\
\hline Very helpful & 4.5 & 4.4 & \\
\hline Somewhat helpful & 7.6 & 9 & \\
\hline Not helpful & 16.7 & 14.1 & \\
\hline Not a source & 71.3 & 72.5 & \\
\hline Teacher & & & $\chi^{2}=11.961, P=0.008$ \\
\hline Very helpful & 64.9 & 59.3 & \\
\hline Somewhat helpful & 22.2 & 25.8 & \\
\hline Not helpful & 4.4 & 6.7 & \\
\hline Not a source & 8.5 & 8.2 & \\
\hline Peer & & & $\chi^{2}=10.748, P=0.013$ \\
\hline Very helpful & 39.5 & 43.5 & \\
\hline Somewhat helpful & 36.2 & 37.7 & \\
\hline Not helpful & 14 & II.I & \\
\hline Not a source & 10.4 & 7.8 & \\
\hline Radio & & & $\chi^{2}=8.717, P=0.033$ \\
\hline Very helpful & 35.1 & 38.7 & \\
\hline Somewhat helpful & 37.3 & 38.4 & \\
\hline Not helpful & 11.2 & 10.2 & \\
\hline Not a source & 16.4 & 12.6 & \\
\hline Television & & & $\chi^{2}=3.117, P=0.374$ \\
\hline Very helpful & 42.7 & 46.3 & \\
\hline Somewhat helpful & 33.1 & 31 & \\
\hline Not helpful & 9.9 & 9.3 & \\
\hline Not a source & 14.3 & 13.4 & \\
\hline
\end{tabular}

impact that unwanted pregnancies and STIs have on reproductive health. The low prevalence of males using a contraceptive method at first, or in repeated sexual relations in Jamaica, is also the case in South Asia, particularly Nepal, ${ }^{24}$ which denotes that there are attitudes and practices among males that extend beyond the Caribbean. It is this attitude (inconsistent condom usage) which explains the fact that $18.2 \%$ of males compared with $11.0 \%$ of females have had STIs. ${ }^{12}$ Another explanation for the STIs disparity between the sexes is the number of sexual partners coupled with inconsistent condom usage. In 2007, Wilks et al found that $55.9 \%$ of males in Jamaica aged between 15-74 years had more than one sexual partner compared with $39.9 \%$ of females of the same age cohort. ${ }^{12}$
Table 3 Logistic regression: Explanatory variables of respondents who currently use contraceptive methods, $n=2,059$

\begin{tabular}{lll}
\hline $\begin{array}{l}\text { Explanatory } \\
\text { variable }\end{array}$ & Odds ratio & Cl (95\%) \\
\hline $\begin{array}{l}\text { Woman pregnant for } \\
\text { respondent ( } \mathrm{I}=\text { yes })\end{array}$ & $0.08^{* * *}$ & 0.040 .16 \\
$\begin{array}{l}\text { Shared sanitary } \\
\text { facility }(\mathrm{I}=\text { yes })\end{array}$ & $0.62^{*}$ & 0.420 .94 \\
$\begin{array}{l}\text { Had sexual intercourse in the } \\
\text { last } 30 \text { days with nonstable }\end{array}$ & $2.00^{* * *}$ & 1.402 .86 \\
partner $(\mathrm{I}=$ yes $)$ & & \\
\hline
\end{tabular}

Notes: -2 Log likelihood $=1032.9 ; \mathrm{R}^{2}=0.103 ;$ Model $\chi^{2}(\mathrm{df}=3)=65.2$; $P$-value $<0.000 \mathrm{I}$; Overall correct classification $=87.8 \%$; Correct classification of cases that currently use a contraceptive method $=98.8 \%$; Correct classification of cases that did not currently use a contraceptive method $=72.3 \%$; $* P<0.05, * * P<0.0$ I, $* * * P<0.001$.

The majority of the men (53\%) stated that they were responsible for supplying the method of contraception. These men may be negotiating their masculine identity during sexual intercourse by taking control over the use of the method of contraception. ${ }^{5}$ Pharmacies are the major outlets for the methods of contraception used, because $69 \%$ of the men get their contraceptives from pharmacies, compared with $16.1 \%$ who get them from health centers and hospitals. The use of the pharmacies suggests a cost to these men. Therefore, the reproductive health policy, which influences the transmission of STIs as well as population growth, should make condoms more readily available in the public health system. The greater availability of condoms free of cost to these men should push the use of condoms beyond the $60.8 \%$ of those who reported that they used a condom during their last sexual intercourse.

The men received information on sex education or family life education from several institutional sources. These institutional sources, in descending order of importance, are teachers, parents, and peers/friends. The fact that radio, television, and printed material were not reported by the men as sources of information about sex and family may be due to the ascendancy of the Internet and the attendant social networking sites as sources of information. Therefore, any education campaign component of a reproductive health policy should use the Internet and social networking sites to disseminate information.

The three significant explanatory factors for the current contraceptive methods used by the men are having someone pregnant, sharing sanitary facilities with a nonhousehold member and having had sexual intercourse in the last 30 days with a nonstable partner. The men were less likely to use a method of contraception when their partner was pregnant. One possible reason for this finding is that some 
men generally prefer to have sex without condoms, and their partners being pregnant provides the opportunity for them to have sex with their pregnant partner without using a condom. The likelihood of the men using a condom decreases when they share sanitary facilities with persons who are not a part of their household. This may occur because using shared sanitary facilities with nonhousehold members provides opportunities for the men to have unplanned and so unprotected sex with women with whom they do not have a blood relationship. The men are more likely to use a method of contraceptive when they have had sexual intercourse in the last 30 days with a nonstable partner. It is possible that these men use a condom because they are not sure of the STI status of the woman, since she is not their steady partner and maybe had sexual intercourse in the last 30 days with other men. It is also possible that these men may not want to father a child with their nonstable partner.

Other studies have shown that the low use of male-based methods has been attributed to lack of awareness of different methods, opposition by husbands, lack of method satisfaction, fear of side effects and poor access to family planning services. ${ }^{25-29}$ However, in the current research we found something of a difference. We found that high contraceptive usage (male-based method) was owing to having had sexual intercourse in the last 30 days with a nonstable partner. However, the low contraceptive method usage was owing to (1) being in a relationship with a woman who is currently pregnant and (2) shared sanitary conveniences. The issue of fear of side effects and lack of a method of satisfaction do not account for the low male-method used by young males in Jamaica as there is an embedded belief that condom usage should be more used with a stranger than a stable partner, which opens the individual to the risk of his partner's lifestyle. Hence, the opposition of females or wives to the use of condoms is also embedded in this study, as they would question the practices of the male partner or their fidelity in the relationship. Therefore policies that are geared towards male reproductive attitudes cannot cease with increased condom usage, as is evident in this study as well as others, ${ }^{18,30-33}$ because clearly the current reproductive health programs are not reaching all the men of Jamaica.

A part of the rationale for why the current reproductive health intervention geared towards males is not reaching them is embedded in the fact that most of the family planning programs are designed primarily to serve women. ${ }^{34,35}$ It is evident that there are many options in methods of contraception for women, compared with those for males. Males are limited to coitus-dependent ones such as the condom or withdrawal, or permanent choices such as vasectomy or hormonal contraceptives. Young males would not be willing to use the latter method, which substantially limits their choices. This limited choice in contraceptive methods for males is fuelling the low usage among them, and it is difficult for family planning methods to effectively reach men of all ages in the world, which is equally the case in Jamaica. Males have a limited choice of methods of male contraception, and if they refuse to use either choice, it means that they are exposing themselves to risky sexual behavior.

\section{Conclusion}

The majority of men currently had sexual intercourse in the last 30 days. Church attendance and age influenced the men's involvement in sexual intercourse, because men who attended church frequently and were younger were more likely to abstain from sexual intercourse. The men used several methods of contraception such as the pill, the rhythm method and condoms, with the majority using the latter contraceptive. The majority of the men had engaged in sexual intercourse in the last 30 days with a nonsteady partner, and a significant minority of these men did not always use a condom, thereby increasing the risk of STIs. The majority of the men claimed responsibility for making the decision about the use of contraceptives, and pharmacies were the most popular outlet from which contraceptives were purchased. The three significant factors that explain the current method of contraception used by the men were having had sexual intercourse in the last 30 days with a nonsteady partner, sharing sanitary facilities with a nonhousehold member and a woman being pregnant for them. A national reproductive health policy is needed to take into account the type of contraceptives used, the institutional sources of sex education, the sources of contraceptives, the risk of STIs, and the three explanatory factors for the methods of contraception used.

\section{Disclosure}

The authors report no conflict of interest with this work.

\section{References}

1. Wambui T, Ek AC, Alehagen S. Perceptions of family planning among low income men in Western Kenya. Int Nurs Rev. 2009;56(3): 340-345.

2. Avogo W, Agadjanian V. Men's social networks and contraception in Ghana. J Biosoc Sci. 2008;40(3):413-429.

3. Harvey SM, Beckman LJ, Browner CH, Sherman CA. Relationship power, decision making, and sexual relations: An exploratory study with couples of Mexican Origin. J Sex Res. 2002;39(4):284-291.

4. Degni F, Mazengo C, Vaskilampi T, Essen B. Religious beliefs among Somali men living in Finland regarding the use of the condom by men and that of other forms of contraception by Women. Eur J Contracept Reprod Health Care. 2008;13(3):298-303. 
5. Castro-Vasquez G, Kishi I. Silence, condoms, and masculinity: Heterosexual Japanese males negotiating contraception. Men Masc. 2007;10(2):153-177.

6. Needle RH. The relationship between first and sexual intercourse and ways of handling contraception among college students. J Am Coll Health Assoc. 1975;24(2):106-111.

7. Chng CL. The male role in contraception: Implications for health education. J Sch Health. 1983;53(3):197201.

8. Thompson MM. Males and male hormonal contraception. Dissertation Abstracts International Section A: Humanities and Social Sciences. 2008;68(12-A):4994.

9. Mi Kim Y. Stimulating men's support for long-term contraception: a campaign in Zimbabwe. J Health Commun. 1997;2(4):271-297.

10. National Family Planning Board. Reproductive Health Survey, 2002 (Jamaica). Kingston: NFPB; 2005.

11. Grossman M. The Demand for Health - A Theoretical and Empirical Investigation. New York, NY: National Bureau of Economic Research; 1972.

12. Wilks R, Younger N, Tulloch-Reid M, McFarlane S, Francis D. Jamaica Health and Lifestyle Survey 2007-8. Kingston: Tropical Medicine Research Institute, University of the West Indies, Mona; 2008.

13. Finer LB, Henshaw SK. Disparities in rates of unintended pregnancy in the United States, 1994 and 2001. Perspect Sex Reprod Health. 2006; 38:90-96.

14. Mosher WD, Martinez GM, Chandra A, Abma JC, Willson SJ. Use of contraception and use of family planning services in the United States, 1982-2002. Adv Data. 2004;350:1-36.

15. International Conference on Population and Development. Programme of Action. New York, NY: United Nations (UN); 1994.

16. Drennan M. Reproductive health: new perspectives on men's participation. Popul Rep J. 1998;46:1-35.

17. Masson OK, Herbert LS. Husbands' versus wives' fertility goals and use of contraception: the influence of gender context in five Asian countries. Demography. 2000;37:299-311.

18. The Alan Guttmacher Institute (AGI). In Their Own Right: Addressing the sexual and reproductive health needs of men. New York, NY: AGI; 2003.

19. Ezeh AC, Seroussi M, Raggers H. Men's Fertility, Contraceptive Use and Reproductive Preferences. Calverton, MD: Macro International, Inc.; 1996.

20. Salem R. Men's Surveys: New findings. Population Reports. Series M, No. 18. Baltimore, MD: Johns Hopkins Bloomberg School of Public Health, the INFO Project; 2004.
21. U.S. Agency for International Development Interagency Gender Working Group. Reaching Men to Improve Reproductive Health For All: Resource guide. Washington, DC: Population Reference Bureau; 2003.

22. Hulton L, Falkingham J. Male contraceptive knowledge and practice: what do we know? Reprod Health Matters. 1996;4(7):90-100.

23. Chevannes B. Learning to be a Man: Culture, socialization and gender identity in five Caribbean communities. Kingston, Jamaica: The University of the West Indies Press; 2001.

24. United Nations. World Contraceptive Use 2005 Wall Chart. New York, NY: Department of Economic and Social Affairs, Population Division, UN; 2005.

25. Casterline JB, Zaba AS, Manhaj MH. Obstacles to contraceptive use in Pakistan: a study in Punjab. Stud Fam Plann. 2001;32(2):95-110.

26. Casterline JB, Sinding SW. Unmet need for family planning in developing countries and implications for population policy. Popul Dev Rev. 2000;26(4):691-723.

27. Bongaarts J, Bruce J. The causes of unmet need for contraception and the social content of services. Stud Fam Plann. 1995;26(2):57-75.

28. Bankole A. Desired fertility and fertility behaviour among the Yoruba of Nigeria: a study of couples' preferences and subsequent fertility. Popul Stud. 1995;49(2):317-328.

29. Shrestha A, Stoeckel J, Tuladhar JM. The KAP gap in Nepal: reasons for non-use of contraception among couples with unmet need for family planning. Asia Pac Popul J. 1991;6(1):25-38.

30. Dahal GP, Padmadas SS, Hinde PRA. Fertility-limiting behavior and contraceptive choice among men in Nepal. Int Fam Plan Perspect. 2008;34(1):6-14.

31. Feyisetan B, Casterline JB. Fertility preferences and contraceptive change in developing countries. Int Fam Plan Perspect. 2000;26(3): $100-109$.

32. Ezeh AC, Seroussi M, Raggers H. Men's Fertility, Contraceptive Use, and Reproductive Preferences. Calverton, MD: Macro International, Inc.; 1996.

33. Roudi F, Ashford L. Men and Family Planning in Africa. Washington, DC: Population Reference Bureau; 1996.

34. Ringheim K. Factors that determine prevalence of use of contraceptive methods for men. Stud Fam Plann. 1993;24:87-99.

35. Ringheim K. Whither methods for men? Emerging gender issues in contraception. Reprod Health Matters. 1996;4:79-89.
Open Access Journal of Contraception

\section{Publish your work in this journal}

Open Access Journal of Contraception is an international, peerreviewed, open access, online journal, publishing original research, reports, reviews and commentaries on all areas of contraception. In addition to clinical research, demographics and health-related aspects, the journal welcomes new findings in animal and preclinical studies

\section{Dovepress}

relating to understanding the biological mechanisms and practical development of new contraceptive agents. The manuscript management system is completely online and includes a very quick and fair peer-review system. Visit http://www.dovepress.com/testimonials.php to read real quotes from published authors. 